\title{
CÁC GIẢI PHÁP RÈN LUYỆN NĂNG LỰC THỰC HÀNH NGHỀ NGHIỆP CHO SINH VIÊN ĐÁP ÚNG CHUẨN ĐẦ RA THEO ĐỀ CƯONG CDIO
}

\author{
Võ Quốc Lương ${ }^{(*)}$ \\ (*) Thạc sĩ. Truò̀ng Đại học Thủ Dầu Một.Email: luongvq@tdmu.edu.vn
}

DOI: $10.37550 /$ tdmu.CFR/2021.01.138

\section{Tóm tắt}

Đào tạo nhân lục đáp úng yêu cầu của xã hội là muc tiêu chung của các co sở giáo dục. Truờng $Đ H$ Thủ Dầu Một triển khai áp dụng đề xuớng CDIO để xác định chuẩn đầu ra (CĐR) cho các ngành đào tạo, trong đó chú trọng năng lục về thực hành nghề nghiẹp cho sinh viên (SV) là CĐR quan trọng. Có thể nói, tiếp cận CDIO là một giải pháp nâng cao chất luợng đào tạo, góp phần rút ngắn khoảng cách giữa giảng dạy và thực tiễn. Tuy nhiên, nó đã đặt ra cho cả người dạy và người học nhũng thách thức lón. Bài viết trình bày thực trạng về năng lực nghề của SV nhóm ngành công nghệ thông tin (CNTT) và nêu lên một số giải pháp đã thực hiện tại Viện Kã thuật Công nghệ nhằm nâng cao năng lục thực hành nghề nghiệp cho SV đáp úng yêu cầu của xã hội.

Từ khóa: Chuẩn đầu ra CDIO, Thục hành, Thực tập, Năng lục nghề nghiệp

\section{Giới thiệu}

Ở các trường đại học, tiếp cận CDIO là cách thức tiếp cận về đào tạo theo định hướng năng lực đầu ra. Mô hình này cung cấp cơ sở khoa học và một hệ thống các tiêu chuẩn chất lượng nhằm giúp cho các cơ sở giáo dục đại học giải quyết 2 vấn đề cơ bản: (1) Dạy $\mathrm{SV}$ cái gì? và (2) Dạy như thế nào để SV lĩnh hội được tri thức? Đây là nhiệm vụ của giáo dục đại học nói chung và đào tạo năng lực nghề nghiệp nói riêng.

Với chiến lược phát triển trường Đại học Thủ Dầu Một trở thành đại học theo định hướng ứng dụng, cùng thực hiện chiến lược đó Viện Kỹ thuật Công nghệ đề ra mục tiêu là đào tạo nguồn nhân lực có chất lượng, thực học, thực làm đáp ứng hiệu quả nhu cầu thị trường lao động. $\mathrm{SV}$ được học và trải nghiệm theo quy trình kiến tạo sản phẩm: Hình thành ý tưởng - Thiết kế - Thực hiện - Vận hành. Qua đó giúp SV đạt được kết quả học tập mong đợi [7]. Để thực hiện mục tiêu này, hàng năm Viện Kỹ thuật Công nghệ đã xây dựng kế hoạch: Bồi dưỡng, nâng cao năng lực của đội ngũ giảng viên $(G V)$, lập kế hoạch để $G V$ thực tập, thực tế tại doanh nghiệp. Ngoài ra, để SV tiếp cận sớm với môi trường nghề nghiệp, Viện đã tổ chức cho $\mathrm{SV}$ tham quan thực tế doanh nghiệp ngay từ năm thứ 1 ; Thực tập doanh nghiệp và làm đồ án cơ sở từ năm thứ 2 ; Thực tập nghề nghiệp từ cuối năm thứ 
3. Với đặc thù của ngành kỹ thuật, khối lượng kiến thức liên quan đến thực hành, thực tập chiếm $50 \%$ toàn bộ chương trình đào tạo (CTĐT), vì thế $\mathrm{SV}$ cần phải rèn luyện kỹ năng thực hành ngay trong từng môn học và duy trì kỹ năng này thường xuyên để vận dụng vào nghề nghiệp tương lai.

Mặc dù kỹ năng thực hành nghề nghiệp (kỹ năng $\mathrm{CDIO}$ ) được rèn luyện thường xuyên qua mỗi môn học, tuy nhiên không phải SV nào cũng có thể vận dụng tốt và linh hoạt kỹ năng: Hình thành ý tưởng, thiết kế, thực hiện, và vận hành trong bối cảnh doanh nghiệp, xã hội và môi trường - quá trình sáng tạo. Qua khảo sát gần $500 \mathrm{SV}$ khối ngành CNTT qua các khóa thì có $38 \% \mathrm{SV}$ cho biết rất khó để tìm ý tưởng của bài toán, $48 \%$ cho rằng sau khi có ý tưởng thì việc cài đặt hoặc thực hiện ý tưởng đó không dễ dàng. Trong bài viết này, chúng tôi trình bày một số giải pháp nhằm rèn luyện và phát triển năng lực thực hành nghề nghiệp cho SV nhóm ngành CNTT ở Viện Kỹ thuật Công nghệ nhằm đáp ứng chuẩn đầu ra theo đề cương CDIO. Nội dung của bài viết tập trung vào ba phần: Thứ nhất trình bày sơ lược về năng lực thực hành nghề nghiệp theo CDIO, phần thứ hai chúng tôi nêu sơ lược về thực trạng về năng lực thực hành nghề nghiệp của SV, phần thứ ba là một số giải pháp và đánh giá kết quả. Cuối cùng là kết luận.

\section{Năng lực thực hành nghề nghiệp theo đề cương CDIO}

Theo cách tiếp cận CDIO, sinh viên khi tốt nghiệp cần đạt được 4 năng lực chính hay còn gọi là $\mathrm{CĐR}$ của chương trình: (1) Khối kiến thức và lập luận ngành; (2) Các kỹ năng và phẩm chất cá nhân và nghề nghiệp; (3) Các kỹ năng và phẩm chất xã hội; (4) Năng lực áp dụng kiến thức vào thực tiễn đặt trong bối cảnh xã hội và doanh nghiệp [1].

\begin{tabular}{|c|c|c|}
\cline { 2 - 3 } \multicolumn{1}{c|}{} & \multicolumn{2}{c|}{ 4. Năng lực nghề nghiệp/ Năng lực CDIO } \\
\hline $\begin{array}{c}\text { 1. Kiến thức và lập luận } \\
\text { ngành }\end{array}$ & $\begin{array}{c}\text { 2. Kỹ năng và phẩm chất cá nhân và } \\
\text { nghề nghiệp }\end{array}$ & $\begin{array}{c}3 . \text { Kỹ năng làm việc nhóm và giao } \\
\text { tiếp }\end{array}$ \\
\hline
\end{tabular}

Hình 1. Chuẩn đầu ra CDIO cấp độ 1 [1]

Nội dung (1) của CĐR giúp người học có được những kiến thức chuyên môn cần thiết, nội dung (2) thể hiện người học tích lũy được những kỹ năng, tố chất cho bản thân mình, nội dung (3) giúp người học có kỹ năng để làm việc trong cộng đồng, xã hội, nội dung (4) tập trung vào năng lực thực hành nghề nghiệp của người học, đây chính là năng lực $\mathrm{CDIO}$ [3].

Hình 1 , cho thấy có sự tương thích giữa $\mathrm{C} Đ \mathrm{R}$ cấp độ 1 của $\mathrm{CDIO}$ với các các trụ cột giáo dục của UNESCO.

Bảng 1. Đối sánh CĐR cấp độ 1 CDIO với các tru cột của UNESCO

\begin{tabular}{|l|l|}
\hline \multicolumn{1}{|c|}{ Chuẩn đầu ra CDIO cấp độ 1 } & \multicolumn{1}{c|}{ Theo UNESCO } \\
\hline 1. Kiến thức và lập luận ngành & Học để biết \\
\hline 2. Kỹ năng và phẩm chất cá nhân và nghề nghiệp & Học để trưởng thành \\
\hline 3. Kỹ năng giao tiếp: làm việc nhóm và giao tiếp & Học để chung sống \\
\hline 4. Năng lực nghề nghiệp/ Năng lực CDIO & Học để làm \\
\hline
\end{tabular}


Trong đề cương CDIO, năng lực thực hành nghề nghiệp được xem là một CĐR quan trọng, CĐR này xem xét đến 6 yếu tố liên quan: (1) Bối cảnh xã hội và môi trường; (2) Bối cảnh tổ chức và nghề nghiệp; (3) Hình thành ý tưởng, kỹ thuật hệ thống và quản lý; (4) Thiết kế; (5) Triển khai; (6) Vận hành. Các yếu tố này được hình thành và rèn luyện thông qua môi trường học tập trải nghiệm - thực hành để SV có thể gắn kết nội dung học tập với nhu cầu của xã hội [2]. Năng lực thực hành nghề nghiệp của SV nhóm ngành CNTT được phát biểu trong $\mathrm{CĐR}$ của CTĐT dựa trên bộ quy định Chuẩn kỹ năng nhân lực CNTT chuyên nghiệp của [4] và tiêu chuẩn về kiến thức, năng lực đối với $\mathrm{SV}$ tốt nghiệp trình độ đại học [5]. Vì vậy trong mỗi môn học của ngành cần phải rèn luyện cho $S V$ thực hành kỹ năng này. Nghĩa là, GV khi lên lớp dạy một bài giảng, hay hướng SV thực hiện một bài tập, xây dựng một sản phẩm,... cần theo quy trình: Hình thành ý tưởng, thiết kế, thực hiện, và vận hành. Có như vậy $\mathrm{SV}$ mới được rèn luyện kỹ năng này thường xuyên, từ đó hình thành kỹ năng, kỹ xảo và có khả năng ứng dụng vào nghề nghiệp sau này.

\section{Thực trạng năng lực nghề nghiệp của sv Viện Kỹ thuật Công nghệ}

Để đánh giá tính hiệu quả của việc vận dụng $\mathrm{CDIO}$ vào giảng dạy, và đo lường mức độ đáp ứng công việc của SV tại các đơn vị tuyển dụng, sau khi SV kết thúc đợt thực tập tại doanh nghiệp, chúng tôi đã tiến hành khảo sát lấy ý kiến của doanh nghiệp về thái độ và năng lực thực hành nghề nghiệp của $\mathrm{SV}$. Kết quả này làm làm căn cứ để các ngành điều chỉnh CTĐT và $\mathrm{CĐR} \mathrm{phù} \mathrm{hợp} \mathrm{với} \mathrm{yêu} \mathrm{cầu} \mathrm{thực} \mathrm{tế.} \mathrm{Sau} \mathrm{đây,} \mathrm{chúng} \mathrm{tôi} \mathrm{tóm} \mathrm{tắt} \mathrm{kết} \mathrm{quả} \mathrm{đánh}$ giá của doanh nghiệp về năng lực của SV từ khóa 2012 đến khóa 2016.

Bảng 2. Kết quả khảo sát ý kiến của doanh nghiệp về năng lục của SV nhóm ngành CNTT [4]

\begin{tabular}{|l|c|c|c|c|c|}
\hline \multirow{2}{*}{ Câu hỏi } & \multicolumn{5}{c|}{ Tỷ lệ \% đồng ý } \\
\cline { 2 - 6 } & $\begin{array}{c}\text { Khóa } \\
\mathbf{2 0 1 2 - 2 0 1 6}\end{array}$ & $\begin{array}{c}\text { Khóa } \\
\mathbf{2 0 1 3 - 2 0 1 7}\end{array}$ & $\begin{array}{c}\text { Khóa } \\
\mathbf{2 0 1 4} \mathbf{- 2 0 1 8}\end{array}$ & $\begin{array}{c}\text { Khóa } \\
\mathbf{2 0 1 5} \text { - 2019 }\end{array}$ & $\begin{array}{c}\text { Khóa } \\
\mathbf{2 0 1 6} \text { - 2020 }\end{array}$ \\
\hline $\begin{array}{l}\text { Khả năng áp dụng kiến thức chuyên } \\
\text { môn trong thực tiê̂n. }\end{array}$ & $53.6 \%$ & $55 \%$ & $59 \%$ & $63 \%$ & $65 \%$ \\
\hline $\begin{array}{l}\text { Khả năng lập kế hoạch, tổ chức và } \\
\text { quản lý một dự án }\end{array}$ & $52 \%$ & $54 \%$ & $54 \%$ & $56 \%$ & $56 \%$ \\
\hline Khả năng giải quyết vấn đề & $56.5 \%$ & $62 \%$ & $65 \%$ & $72 \%$ & $74.2 \%$ \\
\hline Khả năng sáng tạo & $43 \%$ & $43 \%$ & $47 \%$ & $55 \%$ & $56.4 \%$ \\
\hline Khả năng làm việc nhóm hiệu quả & $46 \%$ & $56 \%$ & $61 \%$ & $68 \%$ & $73 \%$ \\
\hline Đạo đức nghề nghiệp và trách nhiệm & $82 \%$ & $85 \%$ & $87 \%$ & $87 \%$ & $88.5 \%$ \\
\hline Khả năng giao tiếp hiệu quả & $70 \%$ & $72.5 \%$ & $76 \%$ & $82 \%$ & $82.5 \%$ \\
\hline $\begin{array}{l}\text { Khả năng tiếp tục phát triển nghề } \\
\text { nghiệp }\end{array}$ & $60 \%$ & $69 \%$ & $73 \%$ & $72 \%$ & $73.1 \%$ \\
\hline Khả năng tư duy độc lập & $65 \%$ & $69 \%$ & $69 \%$ & $68 \%$ & $70.6 \%$ \\
\hline
\end{tabular}

Kết quả ở Bảng 2 chúng tôi thấy rằng, khả năng áp dụng kiến thức vào thực tế của $\mathrm{SV}$ tương đối thấp, chiếm 53.6\% (đối với khóa 2012 - 2016). Bên cạnh đó, những kỹ năng bổ trợ cho nghề nghiệp như: kỹ năng làm việc nhóm, kỹ năng giải quyết vấn đề, khả năng sáng tạo, khả năng giao tiếp... của SV chưa được doanh nghiệp đánh giá cao. Từ thực trạng đó, Viện đã liên tục cải tiến nội dung CTĐT, thay đổi phương pháp giảng dạy, kiểm tra đánh 
giá... nhằm nâng cao chất lượng $\mathrm{SV}$, đáp ứng nhu cầu thực tế của doanh nghiệp. Do đó, kết quả khảo sát các khóa từ 2014 về sau đã chuyển biến rõ rệt. Bản thân SV đã tự tin, chủ động hơn trong học tập và doanh nghiệp cũng có những phản hồi tích cực về điều này. Kết quả trên đã phần nào cho thấy việc thay đổi đã bước đầu có kết quả. Bằng chứng là $\mathrm{CTĐT}$ ngành Kỹ thuật phần mềm và Kỹ thuật điện của Viện chúng tôi đã đạt chuẩn AUN-QA. Tiếp theo chúng tôi sẽ trình bày các biện pháp mà chúng tôi đã áp dụng.

\section{Các giải pháp nhằm nâng cao năng lực thực hành nghề nghiệp cho sv}

\subsection{Nâng cao năng lục của giảng viên bộ môn}

Một yếu tố quan trọng tạo nên sự thành công trong đào tạo đại học là năng lực của GV trong việc tổ chức các hoạt động giảng dạy nhằm giúp SV đạt được nội dung và kết quả học tập mong đợi. Vai trò của $\mathrm{GV}$ càng quan trọng trong quá trình điều phối, hướng dẫn $\mathrm{SV}$ thực hành tại phòng Lab. Đặc thù là khối ngành kỹ thuật nên kỹ năng thực hành là cần thiết đối với SV ngành CNTT, không những lặp lại các thao tác của GV tại lớp hoặc tại phòng Lab mà SV phải tự mình tư duy để tìm phương pháp và giải quyết các tình huống có thể xảy ra khi xây dựng các ứng dụng thực tế.

Theo phương pháp dạy học thực hành được trình bày trong tài liệu [2], một quá trình dạy học thực hành được thực hiện qua ba giai đoạn: giai đoạn chuẩn bị, giai đoạn thực hiện và giai đoạn kết thúc. Tuy nhiên, thông thường, quá trình dạy học theo phương pháp thực hành được áp dụng tại Viện gồm 5 bước: 1) Giảng viên nêu yêu cầu của bài toán (ứng dụng);2) Sinh viên suy nghĩ và đưa ra ý tưởng; 3 ) Phân tích và thiết kế ý tưởng đã có; 4 Cài đặt ứng dụng từ bản thiết kế; 5) Triển khai và đánh giá kết quả.

Với quy trình này, GV không chỉ là người làm mẫu cho $\mathrm{SV}$ quan sát mà phải giám sát, hướng dẫn, chỉnh sửa và đánh giá kết quả thực hiện của SV. Từ đó giúp họ hình thành các kỹ năng, kỹ xảo để áp dụng năng lực đó trong các hoạt động nghề nghiệp sau này. Do vậy, ngoài kiến thức chuyên môn, kỹ năng sư phạm thì năng lực thực hành của GV là một yếu tố quan trọng góp phần giúp SV nâng cao khả năng thực hành nghề nghiệp.

Nắm bắt được tầm quan trọng đó, Nhà trường và Viện đã có văn bản tất cả GV hàng năm phải tiếp cận môi trường thực tế tại doanh nghiệp ít nhất là 2 tháng. Hoạt động này, ngoài mục đích giúp $\mathrm{GV}$ nắm được các công nghệ mới đã và đang được sử dụng tại doanh nghiệp còn giúp họ vận dụng những kiến thức thực tiễn vào nội dung giảng dạy giúp bài giảng sinh động, hấp dẫn và có tính ứng dụng thực tế.

\subsection{Tích họp kiến thức liên môn vào trong một đồ án}

Sản phẩm thực hành của SV ngành CNTT thông thường là một sản phẩm có tính ứng dụng thực tế. Ví dụ: Phần mềm quản lý, Website, Hệ thống CSDL, Mô hình mạng,...Để làm được một sản phẩm như thế $\mathrm{SV}$ cần phải trải qua một quy trình (thường gọi là quy trình làm phần mềm) tương tự như các bước trong kỹ năng $\mathrm{CDIO}$. Thông thường quy trình này gồm các bước cơ bản: Lên ý tưởng; Phân tích; Thiết kế; Cài đặt và Kiểm thử. Tuy nhiên, các bài thực hành của từng môn học riêng lẻ chưa tích hợp đủ các bước trên, GV dạy môn nào sẽ tập trung vào nội dung của môn đó nên sản phẩm chưa có tính ứng dụng cao. Do vậy, nhằm giúp $\mathrm{SV}$ vừa 
thực hành vừa xây dựng được ứng dụng thực tiễn, để từ đó nâng cao khả năng thực hành nghề nghiệp sau này, Viện đã khuyến khích thực hiện các đồ án liên môn. Nghĩa là, mỗi môn học sẽ đảm nhiệm một bước trong quy trình của dự án phần mềm. Chẳng hạn, ở năm thứ $2 \mathrm{SV}$ sẽ được thực hiện đồ án liên môn giữa môn Phân tích thiết kế hệ thống và môn Lập trình Windows để tạo ra sản phẩm Phần mềm quản lý. Trong đó, môn thứ nhất sẽ tập trung vào bước phân tích thiết kế, môn thứ 2 sẽ đánh giá về kết quả cài đặt. Ở năm thứ $3, S V$ tiếp tục làm đồ án liên môn cho môn Thiết kế web và môn Lập trình Web. SV có thể kế thừa kết quả từ môn Thiết kế Web để tiếp tục phát triển đồ án thành một Website hoàn chỉnh. Sang năm thứ 4 , từ các sản phẩm của năm thứ 2 , năm thứ $3, \mathrm{SV}$ tiếp tục học môn Kiểm thử phần mềm. Lúc này đồ án liên môn sẽ tích hợp kiến thức từ phân tích, thiết kế, cài đặt của các môn trước để bước vào giai đoạn kiểm tra và đánh giá sản phẩm... Như vậy, trong một học kỳ, thay vì phải thực hiện 2 hoặc đồ án cho 3 môn học thì nay SV chỉ thực hiện 1 đồ án, nhưng đồ án này lại đòi hỏi SV phải có sự chuẩn bị, tìm hiểu và thực hành đúng quy trình như một dự án thực sự.

Với cách áp dụng này, SV đã hào hứng thực hiện và xây dựng những sản phẩm có chất lượng. Qua khảo sát, với câu hỏi "Khả năng thục hành của bạn được nâng cao khi thực hiện đồ án liên môn?" chúng tôi nhận được $85 \%$ ý kiến đồng ý. Nhiều SV còn hào hứng cho rằng, từ khi áp dụng đồ án tích hợp liên môn, họ có nhiều thời gian để tìm hiểu và thực hiện sản phẩm hơn, khả năng vận dụng kiến thức để thực hành ứng dụng được phát triển cao hơn. Việc thực hiện đồ án theo hướng này sẽ kết hợp được các vấn đề kỹ thuật nghề nghiệp thực tế vào trong bài tập, đồ án chuyên ngành, qua đó SV có thể đưa ra ý tưởng, phân tích, thiết kế và tạo ra sản phẩm, tất cả trong một đồ án.

\subsection{Mô hình Open lab - môi trưòng học tập và thục hành cho SV}

Với SV ngành kỹ thuật, việc thực hành theo thời khóa biểu ở phòng Lab là chưa đủ để rèn luyện và phát triển kỹ năng thực hành. Ngoài thời gian thực hành, thực tập ở trường SV phải tự rèn luyện thêm ở nhà. Tuy nhiên, để hoàn thành một sản phẩm có chất lượng cần phải có sự chia sẻ, góp ý từ thầy cô, bạn bè. Do đó, các bạn cần có một không gian làm việc chung, cùng nhau học, cùng nhau nghiên cứu và cùng nhau sáng tạo [3].

Nhận thấy được nhu cầu đó, từ năm học 2016 - 2017 mô hình Open Lab ra đời. Ban đầu, Open Lab là nơi trao đổi chia sẻ kinh nghiệm học lập trình cho SV năm nhất. Hiện nay, có thể nói đây là nơi "cư trú" hàng ngày của $S V$ các khóa nhằm trao đổi, chia sẻ kinh nghiệm học tập, làm việc nhóm, thực hiện đồ án, ôn tập cho các cuộc thi và thực hiện đề tài nghiên cứu khoa học. Những sản phẩm, giải thưởng các cuộc thi trong các năm qua của Viện cũng được tạo ra từ môi trường này.

\subsection{Thục tập, thục tế cho sinh viên sớm hơn}

Theo kế hoạch đào tạo chung của Nhà trường thì SV sẽ tham gia thực tập tốt nghiệp vào học kỳ cuối của khóa học, đây là hoạt động bắt buộc của tất cả SV các ngành. Trong nội dung của $\mathrm{CTĐT,} \mathrm{SV} \mathrm{sẽ} \mathrm{được} \mathrm{tham} \mathrm{quan} \mathrm{trải} \mathrm{nghiệm} \mathrm{môi} \mathrm{trường} \mathrm{thực} \mathrm{tế} \mathrm{qua} \mathrm{các} \mathrm{môn}$ như Kiến tập, Thực tập doanh nghiệp. Để giúp cho SV hiểu hơn về ngành nghề đang học, cũng như tiếp cận sớm với môi trường làm việc trong tương lại, Viện Kỹ thuật Công nghệ đã lồng ghép buổi tham quan doanh nghiệp ở học kỳ đầu tiên trong học phần Nhập môn ngành. Đây là hoạt động hấp dẫn và thu được nhiều kết quả khả quan. Cảm nhận của SV 
sau chuyến tham quan, học tập rất tích cực, $89 \%$ cho rằng họ đã thấy được quy trình sản xuất phần mềm thực sự chứ không phải qua sách vở.

Bước sang năm thứ $2, \mathrm{SV}$ sẽ trải nghiệm thực tế qua đợt thực tập doanh nghiệp và kết hợp thực hiện đồ án cơ sở ngành. Qua việc cho SV thực hiện sớm đồ án tại năm thứ 2 , bước đầu hình thành cho SV kỹ năng thực hành, thực tập và vận dụng các kiến thức đã học bên trong và bên ngoài Nhà trường để vận dụng vào đồ án của mình. Ngoài ra, từ năm học 2016 - 2017, Viện đã dịch chuyển nội dung thực tập tốt nghiệp lên sớm hơn 1 học kỳ so với kế hoạch đào tạo chung. Nghĩa là thay vì SV sẽ đi thực tập tốt nghiệp vào học kỳ cuối thì sẽ cho $\mathrm{SV}$ đi thực tập vào học kỳ hè của năm thứ 3 . Riêng học kỳ cuối, SV có thể vừa học tập vừa tham gia làm Internship tại các công ty để rèn luyện kỹ năng nghề nghiệp. Có thể nói đây là một điểm khác biệt của chương trình ngành CNTT so với các chương trình khác trong Nhà trường. Nhận thấy được năng lực thực hành nghề nghiệp là quan trọng đối với $\mathrm{SV}$, nên việc cho các em đi thực tế, thực tập sớm sẽ giúp $\mathrm{SV}$ định hướng, lên kế hoạch rèn luyện và phát triển kỹ năng thực hành nhằm đáp ứng nhu cầu công việc trong tương lai.

\section{Kết luận}

Năng lực CDIO là một CĐR quan trọng để đánh giá chất lượng đào tạo của một trường đại học, và đây cũng là một năng lực cần thiết để $\mathrm{SV}$ tự tin ứng tuyển trước nhà tuyển dụng. Chúng tôi đã lồng ghép kỹ năng này vào trong từng nội dung môn học, từng bài thực hành để $\mathrm{SV}$ có thể rèn luyện thường xuyên trong quá trình học tập. Mặc dù vậy, thực tế thì không phải $100 \% \mathrm{SV}$ thành thạo kỹ năng này. Do vậy, bản thân SV phải tự rèn luyện thường xuyên để nâng cao năng lực thực hành trong từng môn học và tích hợp kỹ năng này trong các đồ án chuyên ngành. Ngoài ra, cần có sự chung tay phối hợp của các bên liên quan để thực hiện hiệu quả việc áp dụng đề xướng CDIO trong việc nâng cao năng lực thực hành nghề nghiệp cho SV.

\section{Tài liệu tham khảo}

[1] Cải cách và xây dựng chương trình đào tạo kỹ thuật theo phương pháp tiếp cận $\mathrm{CDIO}, \mathrm{Nxb}$ ĐHQG-HCM, bản dịch tiếng việt từ nguyên bản: E.F. Crawley, J. Malmqvist, S. Östlund, D. Brodeur, Rethinking Engineering Education: The CDIO Approach. Hồ Tấn Nhựt, Đoàn Thị Minh Trinh (biên dịch), 2009.

[2] Dạy học theo tiếp cận “CDIO” trong đào tạo giáo viên kĩ thuật trình độ đại học, Luận án tiến sĩ Khoa học giáo dục, Đỗ Tiến Hưng, 2015.

[3] Dạy và học sâu sắc theo triết lý hòa hợp tích cực, NXB Đại học quốc gia TP. HCM , Nguyễn Văn Hiệp, 2019.

[4] Kết quả khảo sát doanh nghiệp các khóa, Viện Kỹ thuật Công nghệ.

[5] Thông tư số: 11/2015/TT-BTTTT của Bộ Thông tin truyền thông ban hành ngày 05/05/2015 về quy định Chuẩn kỹ năng nhân lực CNTT chuyên nghiệp.

[6] Thông tư số 07/2015/TT-BGDĐT về chuẩn kiến thức, năng lực đối với trình độ tốt nghiệp đại học và sau đại học.

[7] https://et.tdmu.edu.vn/trang-noi-dung/triet-ly-giao-duc, truy cập ngày 10/11/2020. 
